\title{
The Zimbabwe Natural Resources Management Programme and lessons in cross-cultural exchange
}

\author{
G.R. Milne ${ }^{1}$ and A. Hoole ${ }^{2}$
}

Since early 1992, the Ontario Ministry of Natural Resources has been executing a five year, $\$ 19$ million CIDA-funded capacity building programme in the Republic of Zimbabwe, in southern Africa. The programme has a policy development project (EPCU) in the Ministry of Environment and Tourism head office, and an operational level project (RTB) in the Department of Natural Resources. Training and the exchange of skills, knowledge, and experience are critical elements in both projects. The cross-cultural exchange method used by the two Canadian EPCU advisors has evolved from a direct one-on-one approach with only two Zimbabwean counterparts, to a broader approach involving five primary counterparts in the immediate unit, and several secondary counterparts in other branches of the local Ministry. Both approaches have advantages and disadvantages. From experience gained to date however, the broader approach appears better suited for implementing the EPCU project objectives in light of local conditions and constraints.
Depuis le tout début de 1992 , le ministère des Richesses naturelles de l'Ontario est à compléter un programme de cinq ans dont les fonds de 19 millions de dollars ont été avancés par l'ACDI pour la république du Zimbabwe, un pays du sud de l'Afrique. Le programme comporte un projet d'élaboration de politiques (EPCU) au sein du siège social du ministère de l'Environnement et du Tourisme, ainsi qu'un projet de niveau opérationnel (RTB) au sein du ministère des Ressources naturelles. La formation et les échanges au niveau des habiletés, des connaissances et de l'expérience constituent les éléments critiques de ces deux projets. La méthode d'échange interculturel utilisée par les deux conseillers canadiens du projet EPCU a évolué d'une approche individuelle se rapportant à deux correspondants du Zimbabwe, vers un approche plus étendue comportant cinq correspondants de niveau primaire issus de l'unité immédiatement impliquée et quelques correspondants provenant de d'autres départements du ministère local. Ces deux approches compartaient des avantages et des inconvénients. À partir de l'expérience retirée de ce projet à ce jour, l'approche plus étendue semble mieux adaptée à l'implantation des objectifs du projet EPCU en fonction des conditions et des contraintes locales.

\section{Introduction ${ }^{3}$}

The governments of Canada and Ontario are helping the Republic of Zimbabwe to improve its capability for integrating environmental management into sustainable economic and social development. In 1991, Canada, through the Canadian International Development Agency (CIDA), entered a five year, $\$ 19$ million bilateral agreement with Zimbabwe. The agreement lays out a programme to assist Zimbabwe in designing and implementing strategies for environmentally sustainable development. For the past two years, a team of Canadian advisors has worked closely with a number of Zimbabwean counterparts to effect skills exchange and build capacity. This paper presents the programme history and structure, results to date, and lessons learned in cross-cultural skills exchange. The paper focuses on the Environmental Planning and Coordination Project (EPCU) to which the authors are directly attached ${ }^{4}$.

\section{The Zimbabwe Natural Resources Management Programme}

In October, 1991, then Prime Minister of Canada Brian Mulroney announced CIDA and Ontario support for Zimbabwe's

\footnotetext{
${ }^{1}$ Senior Technical Advisor - Environmental Economics, Ontario Ministry of Natural Resources, Zimbabwe Natural Resources Management Programme, EPCU project, Harare.

${ }^{2}$ Senior Technical Advisor - Environmental Planning, Ontario Ministry of Natural Resources, Zimbabwe Natural Resources Management Programme, EPCU Project, Harare.

${ }^{3}$ The authors acknowledge the review of an early draft of this paper by Mr. E.T. Mundangepfupfu, Permanent Secretary, Ministry of Environment and Tourism.

${ }^{4}$ This paper was prepared at the request of the Editor of The Forestry Chronicle, following his visit to Zimbabwe in late 1993.
}

1987 National Conservation Strategy at the Commonwealth First Minister's Conference in Harare, the capital of Zimbabwe. The Prime Minister indicated that CIDA would fund a bilateral programme, and that the Ontario Ministry of Natural Resources (OMNR) would be the executing agency. This initiative is currently CIDA's largest environmental programme in the Southern African region and lessons learned could assist other agencies and countries considering programmes with similar missions.

The programme is structured around two projects (Fig. 1) in the Zimbabwe Ministry of Environment and Tourism (MET). Other agencies within the MET include the Department of Natural Resources, Department of National Parks and Wildlife Management, and two parastatals; the Forestry Commission, and the Zimbabwe Tourist Development Corporation.

The first project is the \$5 million EPCU, located in the Resources Development Branch of the MET headquarters in Harare. Some of the key objectives of this senior policy level project are to:

- help the MET develop and implement new national environmental policy and legislation,

- assist the MET in coordinating development of a national policy, process, and standards for environmental planning and assessment,

- build capacity for socio-economic analysis and other technical skills related to environmental management and policy development in the MET and other organisations, and

- help the MET play a lead role in coordinating the implementation of Zimbabwe's National Conservation Strategy. 


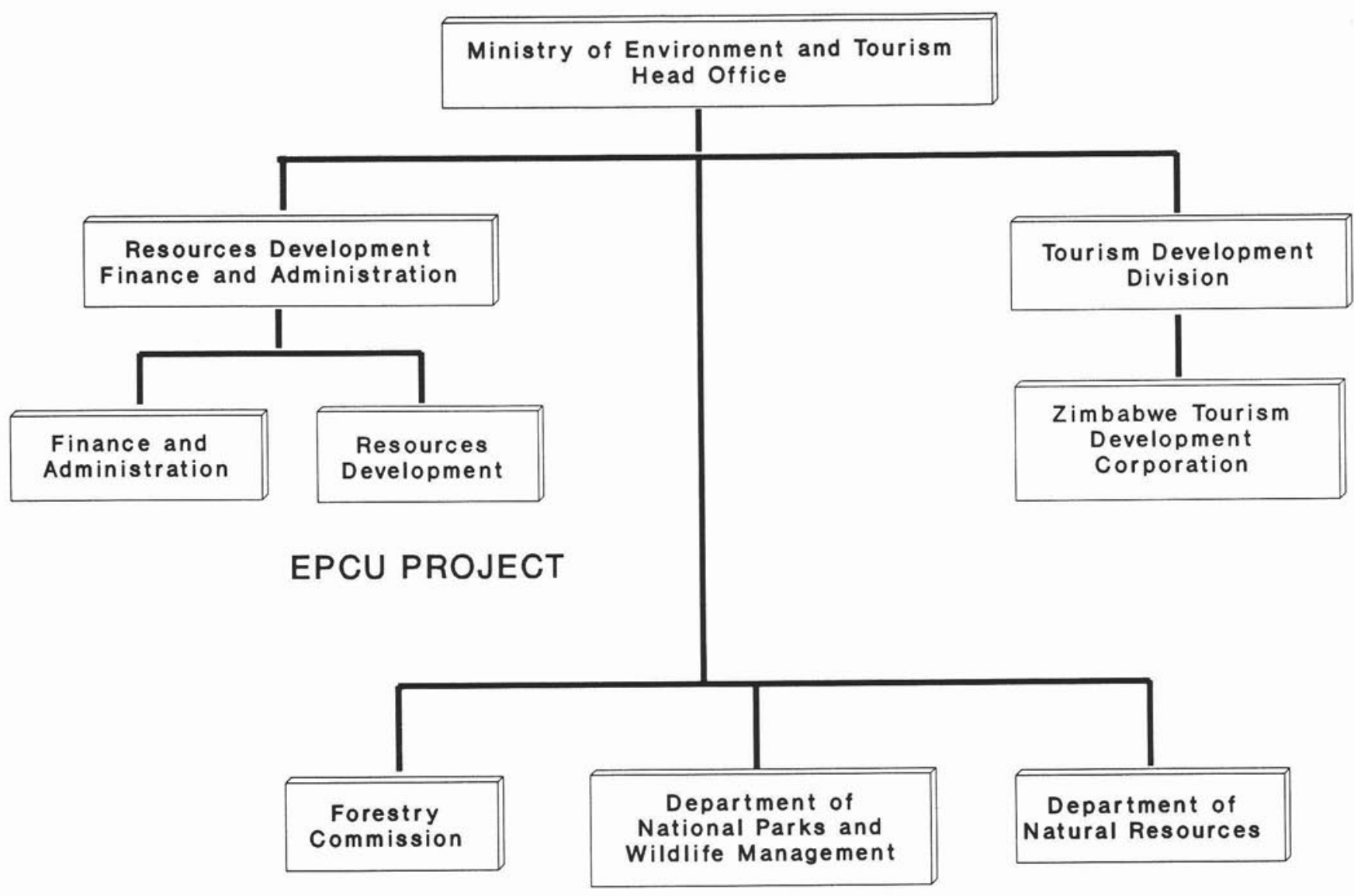

RTB PROJECT

Figure 1. Ministry of Environment and tourism structure and location of EPCU and RTB projects.

The second project is the $\$ 14$ million Research and Technical Branch (RTB) project located in the Department of Natural Resources. The principal objectives of the technical level RTB project are to:

- build technical capacity in the DNR to implement new policies and processes for environmental impact assessment (EIA) of development projects,

- improve the DNR's ability to collect, store, and utilise information on natural resources and resource management, including the development of an integrated resource information system (IRIS), and geographic information system (GIS),

- improve the research capacity and technical skills for monitoring environmental impacts related to industrial and non-industrial development projects,

- develop a modern documentation centre and generate a knowledge base for environmental management research and policy initiatives by the MET and other key agencies.

In December 1991, three senior Canadian technical advisors were recruited by the OMNR through a national competition to join a Programme Director from the OMNR already appoint- ed and assigned to Zimbabwe. These advisors were a Senior Ecologist in the RTB project and, a Senior Environmental Planner and Senior Environmental Economist in the EPCU project. Later in 1992, and early 1993, three additional Canadian technical specialists were recruited for the RTB project in the following areas of expertise; EIA, IRIS/GIS, and Extension/Information. These staff rounded out the full complement of seven Canadians resident in Harare.

\section{Progress to Date RTB Project}

A documentation centre/library has been established in the Department of Natural Resources head office and is being stocked with scientific and technical references. The library uses computer technology for information and literature searches. The library is open to professionals from government and non-government organisations (NGO's) involved in natural resource and environmental management.

The RTB project has made headway towards developing the IRIS/GIS for mapping and resource management in cooperation with other government agencies such as the SurveyorGeneral's Office.

Considerable progress has occurred in building local EIA 
expertise. The RTB staff have given several seminars on EIA to key stakeholders in industry. A course on EIA has also been designed and implemented. A coordinated RTB/EPCU effort towards developing a broader environmental assessment policy has moved forward. The RTB is also playing a major role in an EIA for the Victoria Falls area, one of the continent's most popular tourist destinations.

\section{The EPCU Project}

As an initial step, the EPCU conducted a national survey to identify, clarify and prioritise environmental issues. The results also helped identify and rank national sustainable development objectives. This information has guided MET activities in environmental management and also helped develop local skills in social research and project planning.

The EPCU organised a national report-back conference following the Rio Earth Summit meeting in Brazil to allow input from more than 200 stakeholders to help merge global and national environmental priorities, and identify action programmes. The survey results provided a focal point for many of the discussions at the conference.

The project is assisting the MET lead the implementation of the Montreal Protocol, and coordinate the country response to the World Bank's Global Environment Facility (GEF). The project is also building closer linkages between the MET and the University of Zimbabwe through scholarships for; new graduate programmes in environmental economics, policy and planning; funding for faculty research to address key environmental issues; and the acquisition of references.

An initial EA scoping workshop involving a cross-section of stakeholders was held in April, 1993, followed by the release of a Ministry "prospectus", or discussion paper on EA policy. Following meetings with key stakeholders, a national workshop with more than 250 groups and individuals was held to refine a draft interim policy. A review of current environmental legislation has occurred and Cabinet recently gave the MET a mandate to develop a more comprehensive Environmental Management Act to replace fragmented environmental and natural resource laws now implemented by a number of Ministries. As part of this new mandate the EPCU project is also supporting advanced executive training in strategic planning and organisational change to senior managers. This training and advisory services will help the MET to clarify its future mission, core business areas, resource allocation, and organisational structure.

A quarterly MET environmental newsletter is being published to foster improved communication between various stakeholder groups in the country. As well, a national advisory committee comprising representatives from government, academia, industry, and key NGO's has been formed to share experiences and provide leadership to cross-sectoral sustainable actions.

A programme of policy research and analysis supports these activities. As an example, the team recently developed policy guidelines for canned beverage containers. The guidelines were based on EPCU research and consultations with the beverage industry, leading NGO environmental groups, other key Ministries, the Zimbabwe and South African recycling industry, the Consumer Council, and Standards Association of Zimbabwe.

Twenty-two personal computers and several printers have been installed in both the DNR and the Ministry head office.
All staff who now use computers have, and will continue to receive progressively advanced training in computer operation and various software applications such as word processing, graphics, data bases and spreadsheets.

For both the RTB and EPCU projects, training is a high priority, accounting for around one-quarter of the total budget. The RTB project has sent several Zimbabweans on short-term courses abroad, and implemented a general course on environmental management for Provincial DNR officers. Courses in EIA are also being implemented this year to support the new MET EA policy.

The EPCU has implemented courses in economics and project appraisal, both with a heavy Zimbabwe orientation and focus on local natural resource issues. These courses have been offered to professional staff in various organisations such as the MET, DNR, the Forestry Commission, National Parks and Wildlife, and several NGO's working in the environment and development field. A few Zimbabweans have also been supported in short-term overseas training. Last June, three MET staff came to Canada for a study tour related to environmental assessment and legislation.

Since programme inception, both projects have made significant progress against objectives. A key aspect of overall programme design is counterparting Canadian advisors with Zimbabwean professional staff. At this point, it may be appropriate to review what can be learned from the counterpart approaches used in the EPCU project.

\section{The Counterpart Approach to Skills Exchange}

Some Zimbabweans in government and NGO's have recently expressed criticism of aid projects involving foreign experts. These comments generally pertain to projects where an expatriate advisor is on a short-term consultancy of less than six months to help the host country develop a new policy, implement a new programme, or introduce new technology. In the cases cited, some work is started, usually with a local counterpart, and then the advisor leaves. The host country, government agency, and counterpart staff are ultimately left with the task of implementing the new policy or programme, or using the new technology without the continued guidance and support of the foreign expert. Too often, the policy recommendations are shelved, the new programme fails, and the modern technology is not used effectively.

The criticism also suggests that aid projects should use local expertise where possible rather than parachuting in short-term advisors who are unfamiliar with host country conditions and issues. Even after several months, most consultants and advisors cannot become intimately familiar with local conditions. The money saved by using less expensive local technical advisors could be used for more on-the-ground assistance.

Clearly, short-term projects involving host-country counterparts and foreign advisors can have problems related to cross-cultural effectiveness. Seventy seven percent of CIDA funded advisors work with a local counterpart on both short and long-term projects (Kealey 1990).

Based on our experience to date, we would support many of the concerns raised by critics of short-term aid projects involving foreign consultants. Prior to the Canadian advisors arriving in early 1992, an inception team comprising other Canadians from CIDA and OMNR, and some of the Zimbabweans counterparts, developed a project plan and budget for the two 
projects. When the senior EPCU advisors arrived, a first task was to review and revise the project objectives with the two Zimbabwean counterparts. The EPCU team has just completed another review of the project objectives and budget with a final plan for the remaining three years. These new project objectives and budget allocation are quite different from those set by the team two years ago, and drastically different from those set by the inception team.

The point is that only after gaining substantial local experience, establishing contacts, and learning from local counterparts, can projects be effectively implemented. The project objectives have evolved as more experience is gained both by the Canadians and Zimbabweans on the project. At least one year was required before the Canadian advisors really gained a good sense of local conditions, issues, corporate culture, and other factors. For example we have found that a wealth of local expertise and institution exists for most training needs and to provide short-term assistance in implementing project initiatives in environmental policy, planning, and economics. The inception team budgeted the project based largely on using expensive short-term foreign consultants to assist the resident advisors and Zimbabwean counterparts. The assumption was that foreign experts would have to be brought in for virtually all aspects of the project. This has not been the case and the result has been more project funds spent in the country to implement tasks and build capacity.

When CIDA established the Zimbabwe Natural Resource Management Programme, the problems inherent with short-term counterparts were acknowledged. The new approach would have Canadian advisors work with Zimbabwean counterparts throughout the full five year programme. As originally envisaged, each Canadian would be paired with one Zimbabwean counterpart. The sustained physical presence and guidance of the advisors would improve the chances that new plans, policies, and procedures were successfully implemented. At the same time, both the local counterparts and advisors would mutually exchange valuable skills and knowledge. The Canadians would gain a better understanding of environmental issues in Zimbabwe, institutional arrangements, the local decisionmaking process, and cultural influences in the workplace. On the other hand, the counterparts would have a longer time period to learn new technical and managerial skills. Through this exchange of knowledge, skills, and experiences, both groups would become more effective in achieving programme goals. This approach mirrors recent trends in management and engineering consulting where advisors are often placed in client companies to assist in both the design and implementation of new initiatives.

\section{The EPCU Approach to Counterparts}

The EPCU approach to counterpart strategy has evolved since project inception in early 1992 just as the project goals have changed. The traditional one-on-one counterpart arrangement had already been established and two counterparts placed into the unit when the two Canadian advisors arrived. This approach has since been modified. The Canadians now work with a larger pool of five primary counterparts in the Resources Development Division, and several secondary counterparts in various sections of the Ministry (Fig. 2). As an example, the Canadian advisor in Environmental Planning has worked with staff from both the Resources Development Division and the
Department of National Parks and Wildlife Management on a park planning assignment. The advisor in Environmental Economics has worked with two Division staff and two staff from the Department of Natural Resources on a study of small scale mining. A senior staff member from the Tourism Development Division was sent to a six week course in environmental economics at Harvard University. The rational for this broader counterpart approach was that all five Zimbabweans in the Resources Development Division and key staff in other Branches such as Tourism Development, should benefit from the opportunities presented by this project. Another reason for quickly discarding the traditional approach was that both of the original two direct counterparts in the Resources Development Division expressed interests in acquiring skills somewhat opposite to those represented in their "assigned" advisor.

\section{Advantages and Disadvantages of Each Counterpart Approach}

We recognise that not all capacity building projects can be funded for as long as five years. Some projects are best suited for short time periods and the cost of fielding a team for only a few months will be lower. However, for longer-term projects, different counterpart strategies are possible. What are the relative merits of the approaches evolving in the EPCU project?

\section{One-on-one Counterpart Approach}

With the direct one-on-one approach as originally planned for the EPCU project, both the advisor and single counterpart have more time together to plan, implement, and evaluate specific assignments. The advisor is probably in a better position to judge training needs and develop a long-term training programme for that individual. Conversely, the counterpart is in a better position to identify areas where the advisor needs help to understand local issues and conditions. By working very closely together, highly technical knowledge and skills, such as economic analysis, can be more effectively transferred.

The downside of this approach is that the skills exchange process is limited to only two people. Other local staff who might benefit from closer contact with the advisor but aren't designated as "official counterparts", won't have the same opportunity to learn and develop. Also, if the counterparts receive better pay and conditions of service through the project, resentment may build in the "have nots" who may be of equal rank elsewhere in the organisation. Another problem can arise if the selected local counterpart isn't fully committed to becoming a technical specialist in the field selected for him or her. Local staff can often be named as counterparts because of academic qualifications and existing job status, or they may seek the position due to expectations of better pay and conditions, rather than a deep interest in learning more about a certain technical subject. Also, by focusing time and resources on one counterpart, no organisational depth is being built. If the single counterpart leaves the host organisation for a better position, the capacity building exercise must start over. Where high turnover of local staff is a problem, especially where disparities exist between public and private sector pay, the one-on-one counterpart approach may not be effective in building sustained capacity.

\section{Multiple Counterpart Approach}

With this approach, as now applied in the EPCU project, one advisor works with several local counterparts, sharing skills and 


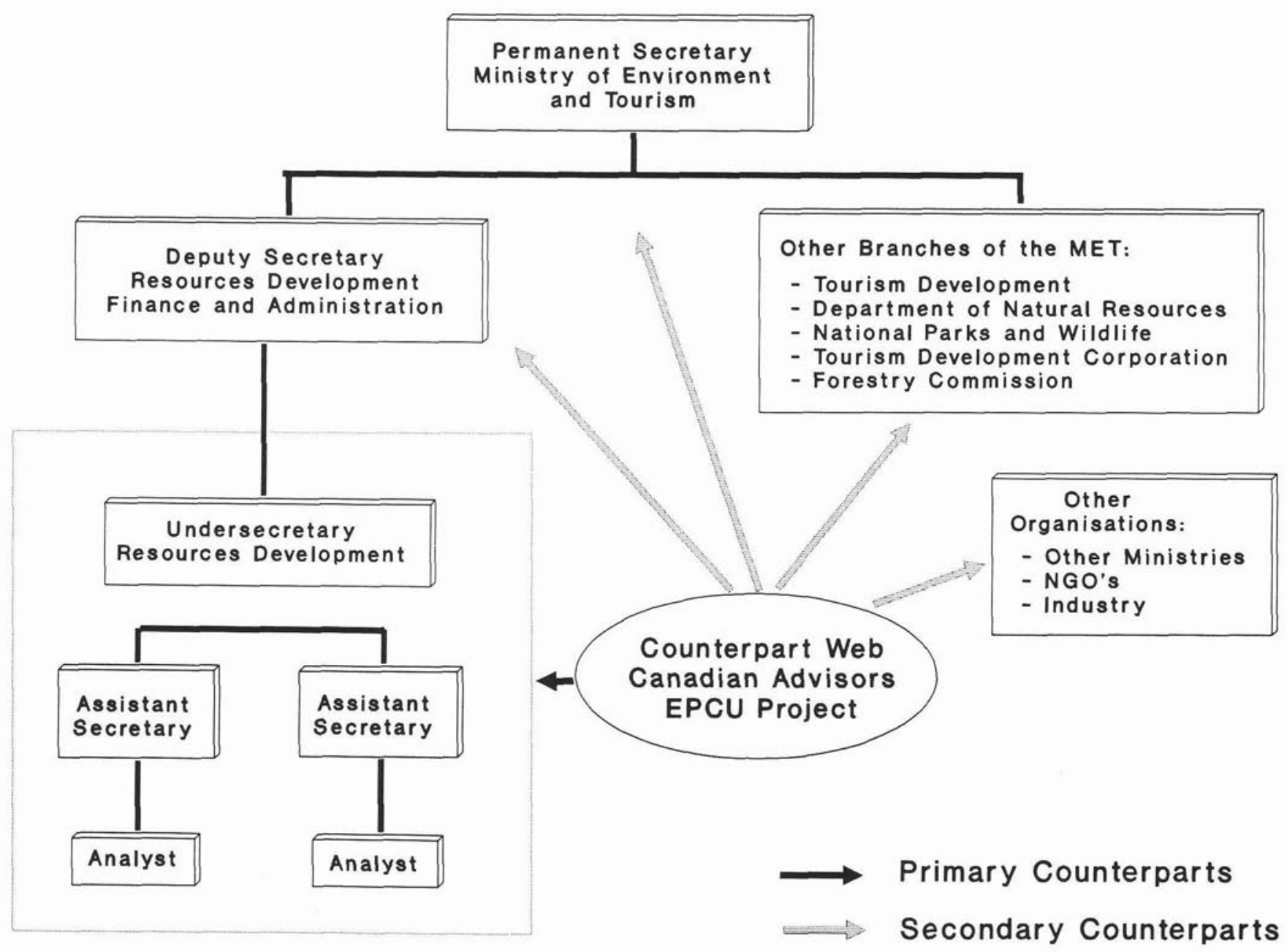

Figure 2. EPCU counterpart web.

knowledge throughout a range of assignments. The advantage of this approach is that the skills of the advisor are diffused more broadly to build depth in the host organisation. If one counterpart leaves, another local staff member can assume responsibilities without a major loss in continuity. This approach also promotes teamwork among local staff who are in the counterpart "pool". Another benefit is that the advisors also gain from exposure to a wider pool of Zimbabweans who have different knowledge and experiences related to local working conditions, country issues, and cultural influences in the work environment. By working with staff from the various branches of the MET and beyond, the advisors develop a wider vision to more effectively guide the project.

The disadvantages of this approach fall mainly onto the shoulders of the advisors, who instead of working with only one main counterpart, now have to consider the needs and attention of several host staff. This approach means extra pressure to advise on several assignments simultaneously. There is less time to spend with each counterpart which can be a constraint on highly technical tasks. While more local staff within the larger counterpart pool gain knowledge and skills, the level of final individual capacity built may be lower than with a direct one-onone approach.

\section{Constraints to Effective Cross-Cultural Exchange}

A number of external factors can constrain effective crosscultural exchange regardless of counterpart approach. These constraints include inadequate human resources, political interference, a lack of qualified local counterparts, and poor equipment (Kealey 1990). Some of these constraints have surfaced in the Zimbabwe project and are being tackled.

The corporate culture in the host organisations must also be recognised as a potential constraint. In Zimbabwe, most decisions in government are made by senior management which can lead to overwork and micro-management. Strategic planning is not common. The lack of an organisational mission and corporate values, clear understanding of core business areas, key stakeholders, clients, and goals inhibits longer-term thinking. Middle management and professional staff often have no authority to make decisions when senior managers are away from the office. Lower-level staff are usually not empowered at all. The result is a slow moving and reactive bureaucracy.

The MET shares some of these corporate culture traits. For the Zimbabwe programme to be fully successful, these constraints must be addressed. Some progress has been made 
over the past year. More gains will occur, especially since the Cabinet recently instructed the MET to review its strategic directions and organisational structure relative to developing and implementing new environmental legislation. The prospect of serious strategic planning bodes well for the MET's future and the sustained viability of many initiatives implemented by the EPCU project.

A larger concern to both projects in the Zimbabwe Natural Resources Management Programme is the growing disparity in the conditions of service (ie. salaries, benefits, etc.) between staff in government and similarly trained people in the private sector and international NGO's located in Zimbabwe. The Zimbabwe government is presently implementing an economic structural adjustment programme (ESAP) where, in addition to liberalising the economy, two key objectives are to trim the size of government and reduce public spending. For counterparts who develop highly marketable skills and gain relevant experience, the possibility of turnover is high. The Zimbabwe government has established a counterpart retention fund to "top up" salaries and benefits, however no funds have yet been secured for counterparts on either project. The idea of a retention fund carries its own set of problems. For example, paying a small and select group of staff a higher wage because they happen to be counterparts could create serious morale problems among a broader range of professional staff who perceive they are being "left out". Also where a broader cross-cultural approach is used as with the EPCU project, defining the counterparts could become an emotive issue.

\section{Conclusions}

The Zimbabwe Natural Resource Management Programme represents a major investment of Canadian aid dollars to build capacity and improve environmental management in Zimbabwe. The programme has a five-year time frame and can therefore alleviate many of the cross-cultural problems associated with traditional short-term aid projects. The programme has made significant progress while grappling with the realities of crosscultural exchange.

The EPCU project to exchange skills with local counterparts has evolved over time. The original and traditional direct one-on-one counterpart approach has been modified to include multiple counterparts for the two advisors. Concurrently, the project objectives and budget allocation have also evolved as experience is gained over time.

The trade-off in these alternate approaches is between developing a few very highly trained local experts (with little depth in the organisation) or training a larger number of less technically advanced staff (but with more depth in the organisation). Each approach has merit and could be applied elsewhere depending upon local conditions and the operating environment. The abilities and personal traits of both the advisors and counterparts are also critical factors to consider. However, no single approach is a guarantee of success. External influences which might inhibit effective cross-cultural exchange in any host country, including Zimbabwe, must be continuously recognised and addressed.

\section{References}

Kealey, Daniel J. 1990. Cross-cultural effectiveness - a study of Canadian technical advisors overseas. CIDA Briefing Centre, Hull, Quebec. 